\title{
The Quality Whirlwind in the Higher Medical Education
}

\author{
Dr., Professor Nino Chikhladze, Dr. Maka Jorbenadze, Nato Pitskhelauri \\ Tbilisi State University, Faculty of Medicine
}

\author{
1, Chavchavadze Av. Tbilisi, 0128, Georgia \\ e-mail: ninoch@tsu.ge \\ tel: (+995-32)39-68-83 \\ fax: (+995-32)22-11-03
}

\section{Introduction}

Globalize World demands realizing Higher Education for making most competitive and dynamic knowledge-based economy, capable of sustainable economic growth with more and better jobs and greater social cohesion.

Higher Education is an important factor in further enhancing research in underpinning Higher Education for the economic and cultural development of our societies and for social cohesion. Effort to introduce structural change and improve the quality of teaching should not detract from the effort to strengthen research and innovation.

Ministers meeting in Berlin in September 2003 added an Action Line to the Bologna process entitled "European Higher Education Area and European Research Area - two pillars of the knowledge based society" that underlines the key role of research training in this context. Bergen Communique (2005) has choose 3 priorities including quality assurance (internal/external quality assurance) and appealed to ,Strengthen research, innovation, emphasis importance of research and research-training" . In London Communique (2007) is marked that „Higher Education Institutions should continue to develop their internal system of quality assurance'".

The task of Higher Medical Education everywhere is the provision of Health Care. Notwithstanding variations, there is a high degree of equivalence of structure, process and product of medical school worldwide.

Research is integral part of Higher Medical Education: increasing the role and relevance of research to technological, social and cultural evolution and to the needs of Society.

\section{Implementation Quality Assurance System in Georgian Higher Educational Area}

According to the Law of Georgia on Higher Education (adopted by the Georgian government in 2005): ,The study and research activity of a higher education institution, as well as the process of upgrading the personnel qualifications, is subject to systematic evaluation in which the students also take part and the results of which shall be public and available for any interested person.

The Quality Assurance Service of a higher education institution closely cooperates with the similar services of foreign higher education institutions in order to establish the transparent criteria for quality control and develop the methodology for meeting these criteria. The higher education institution's Quality Assurance Service ensures the provision of high- quality teaching by introducing modern methods of teaching, learning and evaluation (modules, credit systems, etc.) and prepares self-evaluation for the accreditation process."

Quality Assurance Service at higher education institution should facilitate the process of integration of the Universities with the European Higher Education Area and support 
implementation of the principles of Bologna Process. Accordingly, the Service activity should be based on the standards recognized in Europe.

According to the Law of Georgia on Higher Education (Article 31):

„With the purpose of ensuring systematic evaluation of quality of academic and research activities of the faculty as well as upgrading the personnel qualifications, there shall be established a Quality Assurance Service that shall operate on the basis of the faculty's statute. The Faculty Quality Assurance Service promotes high quality education by introducing modern methods of teaching, learning and evaluation (modules, credit systems, etc.) and prepares self-evaluation for the accreditation process. "

One of the basic duties of the Faculty Quality Assurance Service is modification of the criteria for the assessment of scientific researches with respect to the faculty specifications;

The Quality of Higher Education has proven to be at the heart of the Higher Education. Higher Educational Institutions are urged to continue their efforts to enhance the Quality by their activities through the systematic introduction of internal activities and their direct correlation to external quality assurance.

\section{Research in New Strategic Development Plan of Tbilisi State University}

The century faced the first Georgian University to new demands. University should meet the challenges of the era, develop science and prepare students for further professional activities. Tbilisi State University must be a competitive institution setting high standards of teaching and research within the system of higher education.

New Strategic Development Plan was elaborated in 2006. The given document outlines the main principles and values as the basis of the University development within the coming 5 years. The priorities and posteriorities of teaching and research should be identified. And the main criterion of this process will be the quality of teaching and research.

Improvement of the quality of scientific researches: the main reference point of science and research development must be quality. University pays particular attention to researches directed towards solving complex tasks, and spreading and applying the knowledge acquired as a result of such researches. Fundamental as well as applied science will be developed. Researches done on basic problems of humanity, culture and society should be oriented on problem solving. The main goal of scientific research should be the acquisition of innovative knowledge.

Scientific researches should be defined as the basis for regional, national and international cooperation. University should have at least the function of leading regional scientific center and nurture the expansionist ambition of exporting its education.

Control on the quality of scientific researches will be implemented by means of periodic internal and external evaluations, as well as by various forms of self-evaluation of scientists. Measures:

- Establishment of internal university foundation for scientific researches;

- Organization of interdisciplinary seminars, meetings etc.

- Definition of scientific research plans according to the separate branches;

- Opening a competition for academic positions according to modern scientific directions;

- Elaboration of common conception of university internal evaluation system for scientific research ;

- Acquisition of additional sources;

- Organization of seminars of $\mathrm{PhD}$ researcher;

- Taking into account the possibilities of additional resources while taking academic positions; 
- Organization of trainings and seminars for institutes and faculties on the acquisition of additional resources; methodic support in administering of human and financial resources

- Preserving and developing an individual profile of scientific researches

- Enhancing the relationships between science and business sector

- Developing copyright system

- Activating Cooperation with different non-university centers

- Assisting students' researches

\section{Structure of Higher Medical Education}

The practice of medicine is dynamic and continues to evolve. Medical education represents a continuum of learning that commences with undergraduate medical school and endures until a physician retires from active practice. Its goal is to prepare practitioners of medicine to apply the latest scientific knowledge for the promotion of health and the prevention and cure of human diseases and the mitigation of symptoms of presently incurable diseases. Medical education also comprises the ethical standards governing the thought and behavior of physicians. All physicians have a responsibility to themselves, the profession and their patients to maintain a high standard for their medical education. Medical education consists of basic medical education, postgraduate medical education, and continuing professional development. The profession, the faculties and educational institutions, and the government share the responsibility for guaranteeing that medical education meets a high quality standard throughout this continuum.

The aim of medical education is to develop competent and ethical physicians that deliver high quality healthcare to the public. The goal of basic medical education is to instruct students in the practice of the profession, and to supply the public with well-qualified physicians. The first professional degree should represent the completion of a curriculum that qualifies the student for a spectrum of career choices, including, but not limited to, patient care, public health, clinical or basic research, or medical education. Each of these choices will require additional education beyond the first professional degree. The clinical component of medical education must be centered on the supervised study of patients and must involve direct experiences in the diagnosis and treatment of disease.

Postgraduate medical education, the second phase of medical education, prepares physicians for practice in a medical specialty. Postgraduate medical education focuses on the development of clinical skills and general and professional competencies and on the acquisition of detailed factual knowledge in a medical specialty. This learning process prepares the physician for the independent practice of medicine in that specialty. Postgraduate medical education programs, including Transitional Year programs, are usually called residency programs, and the physicians being educated in them, residents. A resident takes on progressively greater responsibility throughout the course of a residency, consistent with individual growth in clinical experience, knowledge, and skill. The education of resident physicians relies on an integration of didactic activity in a structured curriculum with diagnosis and management of patients under appropriate levels of supervision and scholarly activity aimed at developing and maintaining life-long learning skills. The quality of this experience is directly related to the quality of patient care, which is always the highest priority. Educational quality and patient care quality are interdependent and must be pursued in such a manner that they enhance one another. A proper balance must be maintained so that a program of postgraduate medical education does not rely on residents to meet service needs at the expense of educational objectives. 
In the context of the Bologna Process, doctoral training has gained recently greater importance on the European higher education agenda. In the Berlin Communiqué in 2003, Ministers responsible for higher education added a new action line on higher education and research as two pillars of the knowledge society and emphasized the importance of doctoral programmes as the third cycle in the Bologna Process. Doctoral programmes are considered to be a crucial source of a new generation of researchers and to serve as the main bridge between the European Higher Education and Research Areas. As such, they have become an official and important part of the political agenda in the Bologna Process. However, doctoral training is markedly different from the first and second cycles of higher education. Its main characteristic, which makes it specific, is that the most predominant and essential component of the doctorate is research. Doctoral candidates have to prove their ability to perform original and independent research within a scientific discipline or interdisciplinary collaboration. Individuality, originality and a certain autonomy are important features of the doctorate.

Continuing professional development is defined as the educational activities that serve to maintain, develop, or increase the knowledge, skills, and professional performance and relationships a physician uses to provide services for patients, the public, or the profession. Physicians should strive to further their medical education throughout their careers. These educational experiences are essential to the physician's continuing professional development: to keep abreast of developments in clinical medicine and the health care delivery environment, and to maintain the knowledge and skills necessary to provide high quality care. The goal of continuing professional development is to sustain and enhance the competent physician. Medical schools, hospitals and professional societies all share a responsibility for developing and making available to all physicians effective opportunities for continuing professional development.

Research training and research career development - and the need to increase the number of highly qualified graduates and well trained researchers - are also becoming increasingly important in the debate on strengthening Europe's research capacity and in the discussions on FP7.

\section{World Federation of Medical Education and Standards for Quality Development of Research}

World Federation of Medical Education (WFME) recommends trilogy of global standards in Medical Education. WFME since 1984 has conducted an International Collaborative program for the reorientation of Medical Education.

The purpose of this project was to provide a mechanism for quality improvement in Medical Education, in a global context.

The WFME project International Standards in Medical Education was approved by World Health Organization (WHO) and by World Medical Association (WMA). The final document was adopted in 2001.

The WFME Global Standards presented in trilogy covers all three phase of Medical Education: basic medical education, postgraduate medical education and continuing professional development.

The three documents will provide the essential background material of the World Conference on Medical Education in Copenhagen (2003).

The WFME Global Standards to be framed to specify attainment at two different levels: basic standards of minimum requirement and standards for quality development.

The WFME that the Global Standards are useful for educational institution as their basis for internal evaluation and quality improvement; Global Standards can be used globally as a tool for quality assurance and development Higher Medical Education too. Furthermore internationally 
accepted standards could be used as a basis for national and regional recognition and accreditation for medical schools.

Areas are defined as broad components in the structure, process and outcome of Medical Education and cover:

1. Mission and Objectives;

2. Educational Programme;

3. Assessment of Students;

4. Students

5. Academic Staff/Faculty;

6. Educational Resources;

7. Programme Evaluation;

8. Governance and Administration;

9. Continuous Renewal.

Sub-areas (36 sub-areas) are defined as specific aspects of an area, corresponding to performance indicators. Standards are specified for each sub-area using two levels of attainment: Basic standard-this means that standards must be met by every medical school and fulfillment demonstrated during evaluation of the school; and Standards for Quality Development-this means that standards is in accordance with international consensus about practice for medical schools and basic medical education.

We have studied the reflection of research aspects in basic standards and in standards for quality development.

One of sub-area of Educational Resources is Research. Basic Standards appeals: „The Medical School must have a policy that fosters the relationship between research and education and must describe the research facilities and areas of research proprieties at the institution'. Quality Development Standards appeals: ,,The interaction betwee _ $n$ research and education activities should be reflected in the curriculum and influence current teaching and should encourage and prepare students to engagement in medical research and development."'

In addition Research is considered in three Quality Development Standards.

Statements of Mission and Objectives: The Mission and Objectives should encompass social responsibility, research attainment, community involvement, and address readiness for postgraduate medical training.

Scientific Method: The Curriculum should include elements for training students in scientific thinking and research methods.

Educational Expertise: There should be access to educational experts and evidence demonstrated of use of such expertise for staff development and for research in the discipline of Medical education.

Among 36 sub-areas one sub-area (with one Basic Standards and one Quality Development Standards) directly deals Research, what is not quite enough for define who University should attaint high quality of Research. Herewith it is necessary take into account the Quality improvement indicators of Health Care.

\section{Clinical Practice, Research and Quality of Health Care}

Exist six aims for quality of Health Care: Care should be safe, effective, patient centered, timely, equitable, and efficient. Pryor noted that it was particularly important to balance efficiency with the other quality aims

Ottawa Health Research Institute offered a different approach to quality improvement research. There is a consistent failure to translate research findings into clinical practice, as evidenced by studies showing 30 percent to 40 percent of patients not receiving the care they should and 20 percent to 25 percent of patients receiving unnecessary or potentially harmful care and 
overcoming this failure is a major focus of health care quality improvement. One way to fix this failure, he suggested, would be to instill evidence into clinical practice at a variety of levels: the structural, the organizational, the group or team, and the individual health professional levels. To target the stakeholders at the various levels, different interventions would be needed, depending on the identified barriers. Implementation research can be described as studies of how the uptake of research findings is promoted. Implementation research focuses on the challenge of delivering evidence-based care to patients. The aim is to develop a generalizable evidence base that can be used to improve the implementation of research findings and enhance decision making at the local level. This research is inherently interdisciplinary, involving health care professionals, organization scientists, engineers, and others.

It is possible use Quality Enhancement Research Initiative, what is founded on the principle that practice needs determine the research agenda, and research results determine interventions that improve the quality of patient care. Quality improvement is analyzed using a variety of methods: systematic reviews, controlled trials, case reports, and hybrid quantitative/qualitative reports. The main aims of Quality Enhancement Research Initiative is integrate research, clinical, operational, and policy expertise to improve health care policy.

It is identified three levers to improve quality improvement research. The first is humanistic - that is, the research will ultimately result in better care for patients. The second lever is in the policy arena. Policy levers, such as accreditaÂon or payors providing matching funds for quality improvement research, must be utilized. Quality improvement research can also be leveraged by strategies focused on individual researchers, for example, providing salary support for protected research time or altering tenure and promotion policies to respond to the special barriers of interdisciplinary research. Quality improvement research involves not only those researchers who will become principal investigators but also many other professionals, such as clinician educators and administrators, whose roles and development must also be considered. One important step in achieving this could be recognizing that quality improvement research, as an interdisciplinary field, will require special attention.

\section{Research in Medical Education and Quality Whirlwind}

The goal of Quality Whirlwind is to enhance the quality of research in medical education and to promote its application to educational practice.

Medical education research needs to demonstrate that trainees a)can become lifelong learners; b)ability to identify inadequacies; c) obtain new knowledge and skills; d) translate knowledge into care improvement.

In medical research interdisciplinary collaboration of various research groups is a key to research progress. For example, the Cancer Network serves as a platform for cooperation between different research groups in which also doctoral candidates are involved.

Continuously improve the conduct of medical education research is possible:

by facilitating collaboration among individuals representing a broad range of disciplines who contribute to scholarship in medical education;

by improving the quality of training in medical education research and fostering the continued development of researchers; 
by facilitating the exchange of research findings, disseminating the results of this research, and encouraging their application to educational practice.

\section{Conclusion}

Higher Medical Education will benefit to Society only with synergy between Education and Research. Faculty at institutions have three functions: teaching, research and service and they must spend a substantial portion of their time at each one. Research environment plays an important role in the professional and personal development but also in the institutional development of universities.

Existing Problems show that Integration of Total quality management of research in The Quality Whirlwind of Medical Education is necessary condition for improving Quality of Higher Education. 